\title{
Large for Gestational Age Births Among South Indian Women: Temporal Trend and Risk Factors from 1996 to 2010
}

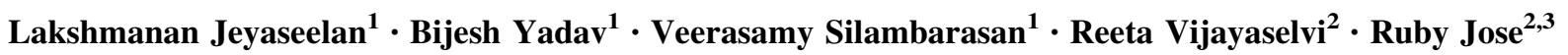

Received: 9 June 2015/Accepted: 13 August 2015/Published online: 8 September 2015

(C) Federation of Obstetric \& Gynecological Societies of India 2015



\begin{abstract}
About the Author
Lakshmanan Jeyaseelan is a Professor of Biostatistics at the Department of Biostatistics, Christian Medical College, Vellore, India, 632002. He was the former Chair of the department (on rotation). He is a Fellow of the International Clinical Epidemiology (INCLEN). He has established Biostatistics Resource and Training Centre (BRTC) in 1998 that trains medical faculty in biostatistical and epidemiological methods. This center has trained over 3000 medical faculty and PG students through short courses on various topics so far. He established Clinical Data Management Centre (CDMC) in 2007, which undertakes data management for vaccine trails and large-scale studies, etc. He developed sample size calculation software "nMaster," which is marketed now in India. He has to his credit about 125 papers published in national and international journals. He is specialized in Bayesian Methods, Bootstrap, Categorical, and Survival data analyses.
\end{abstract}

Lakshmanan Jeyaseelan is a Professor, Bijesh Yadav is a Senior Demonstrator, Veerasamy Silambarasan is a Research Fellow in the Department of Biostatistics, Reeta Vijayaselvi is a Assistant Professor, Ruby Jose is a Professor and Head in the Obstetrics and Gynaecology Unit IV, Christian Medical College, Vellore, India.

Publishing datasets The dataset will not be available for publishing online since further research has been planned.

Ruby Jose

rubyjose1@gmail.com

1 Department of Biostatistics, Christian Medical College, Vellore 632002, India

2 Obstetrics and Gynaecology Unit IV, Christian Medical College, Vellore 632002, India

3 Department of Obstetrics and Gynecology Unit IV, Christian Medical College, Vellore 632004, India

\begin{abstract}
Background/Purpose Mean birth weight is a good health indicator for any population. In the recent past, there have been many reports in the West indicating that there has been an increase in the proportion of large for gestational age (LGA) babies. The objective is to describe the change in the incidence of LGA babies from 1996 to 2010 in South India and the maternal risk factors.

Methods A rotational sampling scheme was used, i.e., the 12 months of the year were divided into 4 quarters and a month was from each quarter was selected rotationally. All deliveries for that month were considered. Only deliveries that occurred between 28 and 42 weeks of pregnancy were considered. The association between risk variables was studied using multivariable logistic regression.

Results There were 35,718 deliveries that occurred during these 15-year-study period in the gestational age 28-42 weeks were registered through the outpatient clinics. The incidence of LGA was $9.4 \%$ that has mostly
\end{abstract}


remained at the same level. The incidence of LGA in mothers with gestational diabetes was $6.7,3$ and $17.6 \%$ in overweight, obese and gestational 1 diabetes mothers. Overweight, obesity in pregnant women and cesarean section were significant risk factors.

Conclusion Unlike in Western countries, where the incidence of LGA babies has spiraled upward, has remained nearly at the same level over one and a half decades, in South India. The risk factors for giving birth to LGA babies in South India were similar to other studies.

Keywords Large for gestational age .

Gestational diabetes - Overweight - Obesity .

Cesarean section and trend

\section{Background}

Mean birth weight is a good health indicator for any population. If the mean birth weight was low, it suggested that the baby had not grown adequately. However, if the babies were large for gestational age (LGA) (mean $+2 \mathrm{SD}$ ) that meant more complications for the mother and the baby. In the recent past, there have been many reports from the West indicating that the mean birth weight of babies had increased considerably [1-5]. Not only has there been an increase in the birth weight of babies, but there has also been an increase in the proportion of LGA babies [6]. The proportion of LGA babies born increased from $8 \%$ in 1978 to $11.5 \%$ in 1995 in Canada. Similarly, in Sweden, from 1992 to 2001, newborn babies weighing over $4500 \mathrm{~g}$ increased from 3.7 to $4.6 \%$, respectively [7]. In China, the incidence of macrosomia, i.e., birth weight $>4000$ or $4500 \mathrm{~g}$, has increased for the period from 1994 to 2000 [8]. Although babies with larger birth weights are preferred by the lay public, it has been shown that neurological sequelae and perinatal death increased as birth weight of the baby crossed $4000 \mathrm{~g}$ [9-11]. Thus, LGA babies were more likely to develop neonatal complications, as well as obesity, diabetes, and cardiovascular diseases later in life [12]. Although the increase in LGA babies seems to be one of the major concerns in the West, there has not been a single report on the magnitude of LGA from India in the recent past.

Some factors cited in the literature for the increased prevalence of LGA were the increase in pre- pregnancy maternal weight, pregestational diabetes, gestational diabetes, the increased gestational weight gain, and reduced smoking prevalence. A study from China reported that the incidence of LGA had partly leveled off due to the increasing use of cesarean deliveries and due to the moderation of gestational weight gain. A study from Sweden reported that prelabor intervention (induction of labor) if the expected birth weight was more than $4000 \mathrm{~g}$ was prevalent [13]. As a result of complications due to LGA or the risk factors that lead to induction of labor for LGA babies, there was an increased risk of cesarean sections, of frequent use of episiotomy, or instrumental delivery and of the increased perineal rupture $[10,11,14,15]$. Therefore, the objectives of this study were to describe the change in the rate of LGA from 1996 to 2010 in India and to study the association between specific maternal risk factors for LGA.

\section{Methods}

\section{Ethical Approval}

The study was approved by the Institutional Review Board of Christian Medical College, Vellore [IRB Min. No. 7109 dated 10. 03. 2010].

\section{Study Site and Population}

The Obstetrics and Gynecology Department of Christian Medical College and Hospital $(\mathrm{CMCH})$, Vellore in the State of Tamil Nadu, India caters to 47,110 outpatients and 15,662 inpatients per year. The Department of Obstetrics and Gynecology had on an average delivered 20 babies per day in 1996 and 40 babies per day in 2010. Women of different socioeconomic status attend this institution for delivery. While the hospital predominantly caters to women patients belonging to the middle and lower socioeconomic strata, those from the higher socioeconomic groups seek care as private patients as well.

\section{Sampling}

To study the trends, for the incidence of LGA babies and the maternal risk factors for the same over a 15 -year period, rotational sampling was used. Detailed description of the sampling is presented in an earlier publication [16].

\section{Antenatal Assessment of Gestational Age}

If menstrual cycles were regular and abdominal examination findings correlated, then the last menstrual period (LMP) was taken as the best estimate of gestational age. If menstrual cycles were irregular or the LMP was unknown, a scan at the first antenatal visit for women in their first and second trimesters was performed, and the gestational age by ultrasound scan was recorded. Hadlock's formula was used for the estimation of gestational age. CRL measurement was used up to 13 weeks of gestation. From 14 weeks gestation onward, the average of the biparietal diameter (BPD), head circumference (HC), femur length (FL), and abdominal circumference (AC) measurements was used 
[17]. Some patients included in the cohort were treated with in vitro fertilization, and their gestation was calculated based on days since oocyte retrieval or co-incubation and adding 14 days [18].

\section{Large for Gestational Age}

For each gestational week of pregnancy, the 90th percentile of the birth weight was calculated. Babies whose birth weight was more than the 90th percentile of the cut-off values specific for gestational ages based on all deliveries that met inclusion criteria, were categorized as LGA. Only deliveries that occurred between 28 and 42 weeks of pregnancy were considered in this study [19].

\section{Inclusion and Exclusion Criteria}

The deliveries of all live births between 28 and 42 weeks of gestation were included, except those of babies with anomalies.

\section{Definitions}

\section{Literacy}

The standard of education was grouped separately for the women and their husbands as (a) nonliterate for those who were unable to read or write; (b) higher secondary for those who had a school education of 12 years; and (c) college and above for those with higher education.

\section{Body Mass Index (BMI)}

BMI was calculated from the weight at delivery using the standard formula: [weight $(\mathrm{kg}) /$ height $(\mathrm{m})^{2}$ ]. Women with a BMI below $18.5 \mathrm{~kg} / \mathrm{m}^{2}$ were classified as underweight, normal weight for BMI of $18.5-24.9 \mathrm{~kg} / \mathrm{m}^{2}$, overweight for $25-29.9 \mathrm{~kg} / \mathrm{m}^{2}$, and obese for BMI $\geq 30 \mathrm{~kg} / \mathrm{m}^{2}$ [20].

\section{Diabetes}

For women with diabetes predating their pregnancy and those with a positive $100 \mathrm{~g}$ 3-h oral glucose, tolerance test was conducted with plasma glucose cut-off values taken at baseline 1, 2, and $3 \mathrm{~h}$ following glucose ingestion. If there were two abnormal values in the oral glucose tolerance test, women were considered as gestational diabetics.

\section{Polyhydramnios}

Women whose ultrasound scan showed a four-quadrant amniotic fluid index of $>25 \mathrm{~cm}$ or a single vertical liquor pocket of $>8 \mathrm{~cm}$.

\section{Birth Weight}

All babies were weighed within an hour of delivery using 111 Braun electronic weighing scale. The scale is calibrated regularly by the engineering department to maintain the consistent accuracy of the scale. The accuracy of the scale being $\pm 0.5 \mathrm{~g}$.

\section{Pre and Postterm}

Delivery at a gestational age between 28 and up to 37 weeks was classified as preterm and that after 42 weeks as postterm.

\section{Statistical Methods}

The association between risk variables and LGA were tested using Chi-square test with Yates correction. The variables which were significant at $p<0.25$, were considered for multivariate logistic regression analysis. Results were presented with OR and $95 \%$ CI. SPSS 16.0 software was used to analyze data.

\section{Results}

Based on rotational sampling method, in total, there were 39,618 deliveries that were sampled during this 15-yearstudy period. Of these, 35,718 deliveries in the gestational age 28-42 weeks were registered through the outpatient clinics, $4443(12.4 \%)$ of them were preterm deliveries. The mean (SD) age of all mothers who delivered between 28 weeks gestation and 42 weeks was 25.2 (4.2) years. The mean (SD) height, weight, and BMI were $155.4 \mathrm{~cm}(6.1)$, $62.9 \mathrm{~kg}$ (11.4), and 26 (4.3), respectively. The prevalence rates of hypertension and gestational diabetes were 3902 (10.9\%) and 2395 (6.7\%), respectively. The mean (SD), median (IQR) of birth weight, and gestation weeks were $2.9 \mathrm{~kg}(0.56), 2.9(2.6,3.2) \mathrm{kg}$, and $38(2.1), 39(38,40)$ weeks, respectively.

A total of $3362(9.4 \%$; $95 \%$ CI 9.1, 9.7\%) LGA babies were observed in this group. There were 18,321 (51\%) male babies and 17,339 (49\%) female babies in the sample. Information on gender was not available for 58 babies. The incidence of LGA in each year for male and female babies with different risk variables is presented in Table 1. The incidence rates of LGA between male and female babies were similar over these years. The incidence rates of LGA were $8.6 \%$ in 1996, $8.8 \%$ in 2010, and nearly $10.5 \%$ during the period 2000-2005. The diagrammatic display of the incidence of LGA and its association with the risk factors are presented in Figs. 1 and 2. The gestational diabetic and obese mothers had higher 
Table 1 Incidence of large for gestational age from year 1996 to 2010 according to gender and risk factors

\begin{tabular}{|c|c|c|c|c|c|c|c|c|c|c|c|c|c|}
\hline \multirow[t]{3}{*}{ Birth year } & \multicolumn{13}{|c|}{ Large for gestational age } \\
\hline & \multirow{2}{*}{$\begin{array}{l}\text { Total delivery } \\
\text { studied }\end{array}$} & \multicolumn{2}{|c|}{ Overall } & \multicolumn{2}{|l|}{ Male } & \multicolumn{2}{|c|}{ Female } & \multicolumn{2}{|c|}{ Teenage $(\leq 19)$} & \multicolumn{2}{|c|}{ Obesity } & \multicolumn{2}{|c|}{ Diabetes } \\
\hline & & $n$ & $\%$ & $n$ & $\%$ & $n$ & $\%$ & $n$ & $\%$ & $n$ & $\%$ & $n$ & $\%$ \\
\hline 1996 & 1610 & 138 & 8.6 & 66 & 8.2 & 72 & 9.0 & 4 & 3.8 & 21 & 16.7 & 14 & 18.7 \\
\hline 1997 & 1682 & 167 & 9.9 & 87 & 10.1 & 80 & 9.9 & 10 & 8.3 & 37 & 22.6 & 18 & 20.7 \\
\hline 1998 & 1801 & 135 & 7.5 & 75 & 8.0 & 60 & 7.0 & 9 & 8.0 & 22 & 13.3 & 27 & 17.1 \\
\hline 1999 & 2000 & 174 & 8.7 & 85 & 8.3 & 89 & 9.1 & 6 & 4.5 & 21 & 12.8 & 21 & 12.3 \\
\hline 2000 & 1893 & 197 & 10.4 & 102 & 10.1 & 95 & 10.8 & 7 & 4.6 & 43 & 19.7 & 36 & 18.9 \\
\hline 2001 & 1829 & 203 & 11.1 & 114 & 12.4 & 89 & 9.7 & 7 & 5.7 & 48 & 17.5 & 31 & 20.7 \\
\hline 2002 & 2345 & 239 & 10.2 & 131 & 10.7 & 108 & 9.6 & 5 & 3.1 & 64 & 19.0 & 47 & 22.8 \\
\hline 2003 & 2588 & 236 & 9.1 & 116 & 8.5 & 120 & 9.8 & 8 & 3.9 & 48 & 15.0 & 23 & 20.2 \\
\hline 2004 & 2695 & 298 & 11.1 & 167 & 12.0 & 131 & 10.1 & 10 & 5.3 & 80 & 19.6 & 25 & 21.0 \\
\hline 2005 & 2313 & 250 & 10.8 & 121 & 10.4 & 129 & 11.2 & 6 & 3.9 & 63 & 17.5 & 27 & 19.0 \\
\hline 2006 & 2449 & 207 & 8.5 & 102 & 8.3 & 105 & 8.7 & 4 & 3.2 & 59 & 11.7 & 15 & 14.0 \\
\hline 2007 & 2826 & 252 & 8.9 & 134 & 9.4 & 118 & 8.5 & 11 & 8.5 & 85 & 15.8 & 37 & 24.0 \\
\hline 2008 & 2766 & 261 & 9.4 & 128 & 9.3 & 133 & 9.6 & 6 & 4.9 & 77 & 13.8 & 46 & 23.0 \\
\hline 2009 & 3165 & 275 & 8.7 & 151 & 9.2 & 124 & 8.2 & 4 & 2.7 & 93 & 14.4 & 39 & 17.0 \\
\hline 2010 & 3755 & 330 & 8.8 & 163 & 8.4 & 167 & 9.2 & 10 & 7.9 & 110 & 14.1 & 49 & 16.7 \\
\hline Total & 35,717 & 3362 & & 1742 & & 1620 & & 107 & & 871 & & 455 & \\
\hline
\end{tabular}

incidence of LGA compared to nongestational diabetic and non-obese mothers.

\section{Demographic Risk Factors}

The distribution of risk variables for LGA babies and the results of multivariable analysis are presented in Table 2. Teenaged mothers had $0.70(0.56-0.88)$ lower odds for giving birth to LGA babies and those mothers aged 2529 years had $1.15(1.05-1.27)$ higher odds of giving birth to LGA babies, compared to mothers in the age group of 20-24 years $(p<0.001)$. As the age increased, the incidence of LGA increased significantly $(p<.001)$.

When considering the relationship of the husband's occupation with their wives giving birth to LGA babies, women whose husbands were involved in business or owned agricultural lands had a significantly higher odds (OR 1.21, 1.09-1.35) of having LGA babies compared to those whose husbands were professionals $(p<0.001)$. With regard to the occupational status of the husbands, $7.9 \%$ were unskilled workers and $10 \%$ were professionals. The risk of delivering LGA babies was 1.2 times higher (1.1-1.4) among those women whose husbands owned agricultural land or were businessmen compared to women whose husbands were professionals $(p<0.001)$.

Regarding literacy of the mothers, 11.7, 9.2, and $9.6 \%$ were professionals, housewives, and unskilled, respectively. A total of $11.2 \%$ mothers had completed a college degree or more compared to $7.6 \%$ of mothers who were nonliterate. As regards their educational levels of husbands, $11 \%$ had completed a college degree or more and $7.2 \%$ were nonliterate.

\section{Obstetric Risk Factors}

The incidence of giving birth to LGA babies among mothers who had gestational diabetes was $8.7 \%$. Women who had gestational diabetes were (OR 2.0; 1.64-2.12) significantly at a higher risk for giving birth to LGA babies compared to women who did not have gestational diabetes $(p<0.001)$. These diabetic mothers had a higher chance of presenting with polyhydramnios, especially those who had suboptimal control of glucose levels. Mothers diagnosed with polyhydramnios during their pregnancies suffered a threefold higher risk of LGA (OR 3.0; 1.15-6.49) compared to women not diagnosed with polyhydramnios $(p=0.02)$. There was a higher odds of delivering an LGA baby by LSCS compared to normal delivery (OR 1.21; $1.10-1.33)(p<0.001)$.

The incidence rates of giving birth to LGA babies in mothers who were overweight and obese were 38.2 and $17.6 \%$, respectively. Overweight and obese women too were $1.96(1.77-2.17)$ and $2.72(2.42-3.04)$ times, respectively, at higher risk for delivering LGA babies compared to women with normal weight $(p<0.001)$. 
Fig. 1 a Incidence of large for gestational Age (LGA) by infant's gender and maternal age from 1996 to 2010 . b Incidence of large for gestational age (LGA) based on maternal age groups from 1996 to 2010


\section{Discussion}

Our study has found that the incidence of LGA babies was $8.6 \%$ in 1996 and remained almost the same at $8.8 \%$ in 2010. However, the period prevalence was about $10 \%$ for the period from 2000 to 2005 . The reason for this change could be attributed to the policy regarding screening for gestational diabetes. Earlier, the policy for screening for gestational diabetes was based on the presence of risk factors alone, but subsequently the policy was changed to universal screening. It is probable that this practice of universal screening helped to effectively diagnose and treat gestational diabetes thereby resulting in the prevalence of LGA babies remaining static. Our data contradict the findings from other hospital-based studies from the West which have highlighted a rise in the proportion of LGA babies over time [1-4]. However, prevalence of LGA babies in obese mothers and gestational diabetics did not show any specific trend.

Maternal factors that could contribute to an increase in LGA babies were maternal weight, gestational weight gain, gestational diabetes, and maternal age. However, Ørskou et al. [13] have reported that the trend of LGA babies in China had leveled off due to an increase in cesarean sections. The CMC hospital where this study was carried out has also shown an increasing trend in the proportion of cesarean sections over the years. The risk of LSCS was 1.2 (1.1-1.3) times significantly higher for women who had LGA babies. The department fairly strictly adheres to the Cochrane recommendation of not inducing early for macrosomia [21].

As has happened in the case of China, this could mean that the rising trend in LGA babies is one of the reasons for the increased cesarean sections. More research in this area is certainly called for.

\section{Diabetes and LGA}

The association of diabetes and large birth weight has been demonstrated in previous cohort studies [6, 12, 22, 23]. Moreover, it has been shown that weight gain during 
Fig. 2 a Incidence of large for gestational age (LGA) in mothers by gestational diabetes status from 1996 to 2010 . b Incidence of large for gestational age (LGA) in mothers by BMI categories from 1996 to 2010
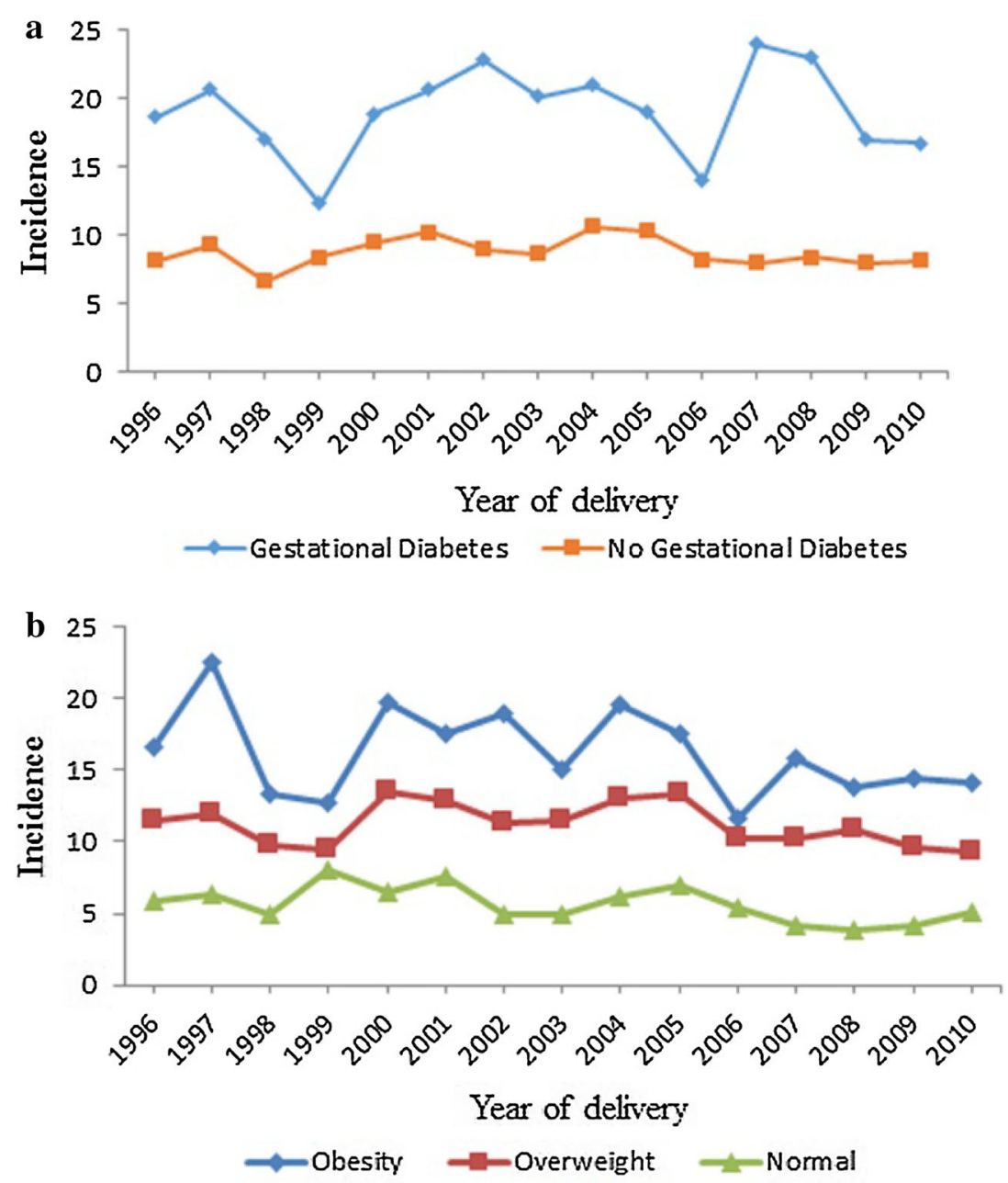

pregnancy is also related to the increased birth weights [24, 25]. Although this study has shown significant association between diabetes and LGA, the data were not based on cohort design, and therefore, this should not be interpreted as causation.

\section{Overweight and Obese Mothers}

Our study found out that overweight and obese pregnant women were at 2-3 times at higher risk for giving birth to LGA babies. Other studies too have reported similar findings. Obesity has long been associated with chronic hypertension and diabetes prior to and during pregnancy. These in turn cause preeclampsia, and gestational diabetes, which can result in cesarean deliveries and prolonged hospital stay [26-32].

Data gathered from the Swedish birth registry have shown that obesity was significantly associated with fetal death and adverse pregnancy outcomes as well [33, 34].

\section{Strengths and Limitations of the Study}

The data for this study were obtained from the labor-room registry of a large referral hospital. The findings are thus the largest observations so far from Asia. Further, we have used international definitions to classify LGA, thereby enabling comparisons with other studies. However, our limited ability to extrapolate the findings of this study to other hospital settings is a drawback. Furthermore, not all women had a dating scan in the first trimester; therefore, very accurate gestational age assignment was not possible. This being a retrospective study, the exact numbers of pregnant women who had a dating scan could not be ascertained. Also, the ideal time to record the baseline height and weight of a pregnant woman is before she has started gaining weight due to gestation. As this is seldom available on a routine database, most researchers have relied on the woman's recall of her prepregnancy height, and weight, the reliability and standardization of which is very doubtful [35]. 
Table 2 Risk factors for large for gestational age based on bivariate (unadjusted) and multivariate (adjusted) analyses

\begin{tabular}{|c|c|c|c|c|c|c|c|c|}
\hline \multirow[t]{4}{*}{ Risk factor variables } & \multicolumn{5}{|c|}{ Unadjusted analysis $(35,718)$} & \multicolumn{3}{|c|}{ Adjusted analysis } \\
\hline & \multicolumn{4}{|l|}{ LGA } & \multirow[t]{3}{*}{$p$ value } & & & \\
\hline & \multicolumn{2}{|l|}{ No } & \multicolumn{2}{|l|}{ Yes } & & \multirow[t]{2}{*}{ OR } & \multirow[t]{2}{*}{$95 \% \mathrm{CI}$} & \multirow[t]{2}{*}{$p$ value } \\
\hline & $n$ & $\%$ & $N$ & $\%$ & & & & \\
\hline \multicolumn{9}{|l|}{ Sex } \\
\hline Male & 16,579 & 90.5 & 1742 & 9.5 & 0.59 & & & \\
\hline Female & 15,719 & 90.7 & 1620 & 9.3 & & & & \\
\hline \multicolumn{9}{|l|}{ Age } \\
\hline $20-24$ & 13,374 & 92.0 & 1159 & 8.0 & & 1.00 & & \\
\hline$\leq 19$ & 1999 & 94.9 & 107 & 5.1 & & 0.70 & $0.56-0.88$ & 0.003 \\
\hline $25-29$ & 11,919 & 89.3 & 1428 & 10.7 & $<0.001$ & 1.15 & $1.05-1.27$ & 0.003 \\
\hline $30-34$ & 4012 & 88.1 & 543 & 11.9 & & 1.11 & $0.97-1.26$ & 0.13 \\
\hline$\geq 35$ & 942 & 89.1 & 115 & 10.9 & & 0.90 & $0.70-1.16$ & 0.41 \\
\hline \multicolumn{9}{|l|}{ Husband occupation } \\
\hline Professional & 15,311 & 90.0 & 1709 & 10.0 & & 1.00 & & \\
\hline Agriculture/business & 5437 & 89.2 & 658 & 10.8 & $<0.001$ & 1.21 & $1.09-1.35$ & $<0.001$ \\
\hline Unskilled/others & 10,686 & 92.1 & 912 & 7.9 & & 0.96 & $0.85-1.07$ & 0.47 \\
\hline \multicolumn{9}{|l|}{ Husband education } \\
\hline Degree and above & 11,893 & 89.0 & 1477 & 11.0 & & 1.00 & & \\
\hline Higher secondary & 16,462 & 91.5 & 1522 & 8.5 & $<0.001$ & 0.92 & $0.83-1.03$ & 0.17 \\
\hline Illiterate & 1293 & 92.8 & 101 & 7.2 & & 0.95 & $0.72-1.26$ & 0.73 \\
\hline \multicolumn{9}{|l|}{ Mother occupation } \\
\hline Professional & 2578 & 88.3 & 340 & 11.7 & & 1.00 & & \\
\hline Housewife & 29,119 & 90.8 & 2960 & 9.2 & $<0.001$ & 0.95 & $0.82-1.10$ & 0.49 \\
\hline Unskilled/others & 253 & 90.4 & 27 & 9.6 & & 1.10 & $0.67-1.28$ & 0.71 \\
\hline \multicolumn{9}{|l|}{ Mother education } \\
\hline Degree and above & 10,221 & 88.8 & 1288 & 11.2 & & 1.00 & & \\
\hline Higher secondary & 18,299 & 91.4 & 1735 & 8.6 & $<0.001$ & 1.01 & $0.90-1.12$ & 0.97 \\
\hline Illiterate & 1244 & 92.4 & 103 & 7.6 & & 0.86 & $0.65-1.15$ & 0.32 \\
\hline \multicolumn{9}{|l|}{ Gestational diabetes } \\
\hline No & 30,416 & 91.3 & 2907 & 8.7 & $<0.001$ & 1.00 & & \\
\hline Yes & 1940 & 81.0 & 455 & 19.0 & & 1.87 & $1.65-2.12$ & $<0.001$ \\
\hline \multicolumn{9}{|l|}{ Induction } \\
\hline Spontaneous & 22,913 & 90.5 & 2409 & 9.5 & 0.31 & & & \\
\hline Induction & 9443 & 90.8 & 953 & 9.2 & & & & \\
\hline \multicolumn{9}{|l|}{ Polyhydramnios } \\
\hline No & 32,321 & 90.6 & 3351 & 9.4 & 0.01 & 1.00 & & \\
\hline Yes & 35 & 76.1 & 11 & 23.9 & & 2.74 & $1.15-6.49$ & 0.02 \\
\hline \multicolumn{9}{|l|}{$N$ preterm delivery } \\
\hline No & 28,276 & 90.4 & 2999 & 9.6 & 0.002 & 1.00 & & \\
\hline Yes & 4080 & 91.8 & 363 & 8.2 & & 0.88 & $0.77-1.01$ & 0.06 \\
\hline \multicolumn{9}{|l|}{ Type of delivery } \\
\hline Normal & 19,772 & 91.5 & 1840 & 8.5 & & 1.00 & & \\
\hline LSCS & 8017 & 88.3 & 1060 & 11.7 & $<0.001$ & 1.21 & $1.10-1.34$ & $<0.001$ \\
\hline Instrumental & 4143 & 90.2 & 450 & 9.9 & & 1.07 & $0.95-1.21$ & 0.28 \\
\hline BMI & & & & & & & & \\
\hline Normal weight & 12,595 & 94.4 & 752 & 5.6 & & 1.00 & & \\
\hline Underweight & 572 & 95.8 & 25 & 4.2 & $<0.001$ & 0.67 & $0.41-1.07$ & 0.09 \\
\hline
\end{tabular}


Table 2 continued

\begin{tabular}{|c|c|c|c|c|c|c|c|c|}
\hline \multirow[t]{4}{*}{ Risk factor variables } & \multicolumn{5}{|c|}{ Unadjusted analysis $(35,718)$} & \multirow{2}{*}{\multicolumn{3}{|c|}{ Adjusted analysis }} \\
\hline & \multicolumn{4}{|l|}{ LGA } & \multirow[t]{3}{*}{$p$ value } & & & \\
\hline & \multicolumn{2}{|l|}{ No } & \multicolumn{2}{|l|}{ Yes } & & \multirow[t]{2}{*}{ OR } & \multirow[t]{2}{*}{$95 \% \mathrm{CI}$} & \multirow[t]{2}{*}{$p$ value } \\
\hline & $n$ & $\%$ & $N$ & $\%$ & & & & \\
\hline Overweight & 10,701 & 88.9 & 1333 & 11.1 & & 1.96 & $1.77-2.17$ & $<0.001$ \\
\hline Obesity & 4692 & 84.3 & 871 & 15.7 & & 2.72 & $2.42-3.04$ & $<0.001$ \\
\hline
\end{tabular}

Bold value indicates reference category

Despite the fact that the CMC hospital is a major referral hospital, its clientele predominantly comprise people belonging to the low and middle socioeconomic strata. Women from the very poor sections of the society may not be represented here.

In this study, BMI at the time of delivery was used. Being a retrospective study, the prepregnancy BMI and the gestational weight gain could not be accessed for further comments.

\section{Conclusion}

This study has concluded that, unlike in Western countries, the incidence of LGA babies has remained nearly the same for over a decade and a half in spite of economic advancement. The risk factors for LGA babies in South India were similar to other studies. Therefore, a good screening program has to be developed based on the risk factors to contain the consequences of for LGA babies.

\begin{abstract}
Acknowledgments The authors acknowledge the support and cooperation extended by the Heads of Obstetrics and Gynecology Department Units 3 and 5 of CMC for sharing their data with us. I sincerely thank and acknowledge the help rendered by Dr. Shuba Kumar (Social Scientist, SAMARTH, NGO, Chennai, India) in proof reading the manuscript. All the contributions by the authors to the research work were voluntary and not funded by any organization. The data were collected by the Clinical Data Management Centre, the Department of Biostatistics, Christian Medical College, Vellore.
\end{abstract}

Authors' contributions LJ was involved in phrasing the research questions. He was involved in the verification of analytic results, which were done by BY and SV. He was involved in drafting the methods section. He also participated in the interpretation of results section along with RJ. BY was Involved in data abstraction supervision, and quality control assurance. He was also involved in data analyses and interpretation. He was further involved in the literature review and drafting the Background section. VS was involved in developing data entry system in EPIINFO and involved in Data Validation part. He was also involved in data analyses and verified the analytic codes. RV was involved in drafting the Background section along with BY. She was involved in the literature review and guiding the Biostatisticians in analyses. She was also involved in writing the Discussion section. RJ has provided leadership in phrasing the research question, was involved in designing the methods of data abstraction and verified the results, and drafted the Discussion section, reviewed, and approved the overall manuscript.

\section{Compliance with Ethical Standards}

Conflict of Interest Dr. Lakshmanan Jeyaseelan (LJ), Bijesh Yadav (BY), Veerasamy Silambarasan (VS), Dr. Reeta Vijayaaselvi (RV) and Dr. Ruby Jose (RJ) declare that they have no conflict of interests.

Ethical Standards The study was approved by the Institutional Review Board of Christian Medical College, Vellore [IRB Min. No. 7109 dated 10.03.2010].

Informed Consent The Institutional Review Board of Christian Medical College Vellore provided consent for this research paper as recorded in the following minutes (IRB Min. No. 7109 dated 10.03.2010).

\section{References}

1. Arbuckle TE, Sherman GJ. An analysis of birth weight by gestational age in Canada. CMAJ 1989;140(2):157-60, 65.

2. Alberman E. Are our babies becoming bigger? J R Soc Med. 1991;84(5):257-60.

3. Power C. National trends in birth weight: implications for future adult disease. BMJ. 1994;308(6939):1270-1.

4. Oja H, Koiranen M, Rantakallio P. Fitting mixture models to birth weight data: a case study. Biometrics. 1991;47(3):883-97.

5. Blondel B, Bréart G, du Mazaubrun C, et al. The perinatal situation in France. Trends between 1981 and 1995. J Gynecol Obstet Biol Reprod. 1997;26(8):770-80.

6. Kramer MS, Morin I, Yang H, et al. Why are babies getting bigger? Temporal trends in fetal growth and its determinants. J Pediatr. 2002;141(4):538-42.

7. Hadfield RM, Lain SJ, Simpson JM, et al. Are babies getting bigger? An analysis of birthweight trends in New South Wales, 1990-2005. Med J Aust. 2009;190(6):312-5.

8. Lu Y, Zhang J, Lu X, et al. Secular trends of macrosomia in southeast China, 1994-2005. BMC Public Health. 2011;11: 818.

9. Bryant DR, Leonardi MR, Landwehr JB, et al. Limited usefulness of fetal weight in predicting neonatal brachial plexus injury. Am J Obstet Gynecol. 1998;179(3 Pt 1):686-9.

10. Axelsson O. Delivery of the large fetus. Acta Obstet Gynecol Scand. 1990;69(6):473-4.

11. Spellacy WN, Miller S, Winegar A, et al. Macrosomia-maternal characteristics and infant complications. Obstet Gynecol. 1985;66(2):158-61. 
12. Das UG, Sysyn GD. Abnormal fetal growth: intrauterine growth retardation, small for gestational age, large for gestational age. Pediatr Clin North Am. 2004;51(3):639-54.

13. Ørskou J, Kesmodel U, Henriksen TB, et al. An increasing proportion of infants weigh more than 4000 grams at birth. Acta Obstet Gynecol Scand. 2001;80(10):931-6.

14. Lawoyin TO. A prospective study on some factors which influence the delivery of large babies. J Trop Med Hyg. 1993; 96(6):352-6.

15. Zetterström J, López A, Anzén B, et al. Anal sphincter tears at vaginal delivery: risk factors and clinical outcome of primary repair. Obstet Gynecol. 1999;94(1):21-8.

16. Kumar VS, Jeyaseelan L, Sebastian T, et al. New birth weight reference standards customised to birth order and sex of babies from South India. BMC Pregnancy Childbirth. 2013;13:38.

17. Hadlock FP, Harrist RB, Martinez-Poyer J. In utero analysis of fetal growth: a sonographic weight standard. Radiology. 1991;181(1):129-33.

18. Definition of Term Pregnancy. The American College of Obstetricians and Gynecologists Committee on Obstetric Practice Society for Maternal-Fetal Medicine. Number 579. November 2013[Internet]. Available from: http://www.acog.org/ResourcesAnd-Publications/Committee-Opinions/Committee-on-ObstetricPractice/Definition-of-Term-Pregnancy.

19. Mehta M, Pattanayak RD. Follow-up for improving psychological well-being for women after a miscarriage: RHL Commentary (last revised: 1 January 2013). The WHO Reproductive Health Library; Geneva: World Health Organization.

20. WHO Expert Consultation. Appropriate body-mass index for Asian populations and its implications for policy and intervention strategies. Lancet. 2004;363(9403):157-63.

21. Irion $\mathrm{O}$, Boulvain $\mathrm{M}$. Induction of labour for suspected fetal macrosomia. Cochrane Database Syst Rev 2000;(2):CD000938.

22. Giapros V, Evagelidou E, Challa A, et al. Serum adiponectin and leptin levels and insulin resistance in children born large for gestational age are affected by the degree of overweight. Clin Endocrinol (Oxf). 2007;66(3):353-9.

23. Surkan PJ, Hsieh C-C, Johansson ALV, et al. Reasons for increasing trends in large for gestational age births. Obstet Gynecol. 2004;104(4):720-6.
24. Hedderson MM, Weiss NS, Sacks DA, et al. Pregnancy weight gain and risk of neonatal complications: macrosomia, hypoglycemia, and hyperbilirubinemia. Obstet Gynecol. 2006;108(5): 1153-61.

25. Siega-Riz AM, Viswanathan M, Moos M-K, et al. A systematic review of outcomes of maternal weight gain according to the Institute of Medicine recommendations: birthweight, fetal growth, and postpartum weight retention. Am J Obstet Gynecol. 2009;201(4):339.e1-14.

26. Ehrenberg HM, Dierker L, Milluzzi C, et al. Prevalence of maternal obesity in an urban center. Am J Obstet Gynecol. 2002;187(5):1189-93.

27. Isaacs JD, Magann EF, Martin RW, et al. Obstetric challenges of massive obesity complicating pregnancy. J Perinatol. 1994;14(1): $10-4$.

28. Galtier-Dereure F, Boegner C, Bringer J. Obesity and pregnancy: complications and cost. Am J Clin Nutr. 2000;71(5 Suppl): 1242S-8S.

29. Sebire NJ, Jolly M, Harris JP, et al. Maternal obesity and pregnancy outcome: a study of 287,213 pregnancies in London. Int J Obes Relat Metab Disord. 2001;25(8):1175-82.

30. Crane SS, Wojtowycz MA, Dye TD, et al. Association between pre-pregnancy obesity and the risk of cesarean delivery. Obstet Gynecol. 1997;89(2):213-6.

31. Johnson SR, Kolberg BH, Varner MW, et al. Maternal obesity and pregnancy. Surg Gynecol Obstet. 1987;164(5):431-7.

32. Bianco AT, Smilen SW, Davis Y, et al. Pregnancy outcome and weight gain recommendations for the morbidly obese woman. Obstet Gynecol. 1998;91(1):97-102.

33. Cnattingius S, Bergström R, Lipworth L, et al. Prepregnancy weight and the risk of adverse pregnancy outcomes. N Engl J Med. 1998;338(3):147-52.

34. Cedergren MI. Maternal morbid obesity and the risk of adverse pregnancy outcome. Obstet Gynecol. 2004;103(2):219-24.

35. Lederman SA, Paxton A. Maternal reporting of pre pregnancy weight and birth outcome: consistency and completeness compared with the clinical record. Maternal Child Health J. 1998;2(2):123-6. 